

\section{O TUTORIAL (MENTORING) NA FORMAÇÃO DO ENFERMEIRO}

EL TUTORIAL (MENTORING] EN LA EDUCACIÓN DE ENFERMERÍA

FULL TIME SCHOOL: AN EXPERIENCE OF YOUTH PROTAGONISM

Ana Paula Rebelo Aquino Rodrigues ${ }^{1}$ Maria Viviane Lisboa de Vasconcelos ${ }^{2}$ Renato Santos Rodarte ${ }^{3}$

\section{RESUMO}

Este estudo propôs demonstrar o tutorial (mentoring) como metodologia de aprendizagem para a formação em Enfermagem. Realizou-se um Estudo de Caso com abordagem metodológica quantitativa e qualitativa. Os sujeitos da pesquisa foram os estudantes do segundo e quinto ano de um curso em enfermagem. A construção dos dados se deu por meio de um questionário estruturado e descrição de uma situação-problema. Os dados quantitativos foram analisados pelo teste não paramétrico de Kruskal Wallis e os dados construídos por meio da resposta à situação problema foram submetidos à análise de conteúdo. Os resultados mostraram a contribuição positiva do tutorial na formação do enfermeiro, possibilitando o desenvolvimento de um pensamento crítico e mais autonomia ao tratar da realidade.

\section{PALAVRAS-CHAVE}

Tutorial. Metodologias. Aprendizagem. 


\section{ABSTRACTO}

Este estudio tuvo como objetivo demostrar el tutorial (mentoring) como metodología de aprendizaje para la formación en enfermería. Se realizó un estudio de caso con enfoque metodológico cuantitativo y cualitativo. Los sujetos fueron alumnos del segundo y quinto año de un curso de enfermería. La construcción de los datos fue a través de un cuestionario estructurado y la descripción de una situación problemática. Los datos cuantitativos se analizaron mediante la prueba no paramétrica de Kruskal Wallis y datos construidos por la respuesta a la situación problemática se sometieron a análisis de contenido. Los resultados mostraron la contribución positiva tutorial en la educación de enfermería que permite el desarrollo del pensamiento crítico y la autonomía cuando se trata de la realidad.

\section{PALABRAS CLAVE}

Tutorial. Metodologías. Aprendizaje.

\section{ABSTRACT}

One of the challenges for institutional education today concerns about adding cognitive dimension to a critical and ethical training. The purpose of this article is to describe details of the students' leadership in the full-time school environment and understand the sociological phenomena involved in the process: empathy, solidarity and mobilization of the entire school community to help a classmate to overcome a family problem. Goleman and Senge's researches (2015) in emotional intelligence point out that the social and emotional learning complement the academic life and theoretical assumptions. Libâneo, Oliveira and Toschi (2003) justify the knowledge self socio construction from the autonomous thinking development and creative attitude. The methodological use of oral history and the youth leaders' narrative serve to the purpose of restoring the details and providing the interviewees the reframing senses of the experienced and new learning for life in accordance with the Delory-Momberger's research (2008). The experience led to the group to maturity and emotional intelligence mainly and the ability to think reflexively, take on challenges, plan actions, and mobilize an entire school community to achieve its purpose.

\section{KEYWORDS}

Education. Youth Leadership. School Environment. Neuroscience. Emotional Intelligence. 


\section{INTRODUÇ̄̃̃O}

A relevância de se ter egressos das profissões de saúde com conhecimento crítico sobre a realidade da saúde é ressaltada pela Legislação que regula o sistema de saúde do país e que estes profissionais possam ao longo de sua formação acadêmica desenvolver, por meio da vivência do Sistema Único de Saúde (SUS), uma aprendizagem significativa que leve a uma capacidade crítica desta realidade (BRASIL, 1990). Isto levou à "necessidade de uma reestruturação dos cursos de graduação com mudanças paradigmáticas no contexto acadêmico, direcionando a Construção de Diretrizes Curriculares para cada Curso de Graduação" (FERNANDES et al., 2005, p. 444).

As Diretrizes Curriculares Nacionais (DCN) trazem que os profissionais em geral devem desenvolver competências no campo da tomada de decisões, da comunicação, da liderança e do gerenciamento. Tendo em vista a velocidade da produção de novos conhecimentos é indispensável que estes profissionais aprendam a aprender (FEURWERKER, 2003) e que esta necessidade do aprendizado deve ser estimulada desde a vida acadêmica.

Toda esta discussão sobre a aprendizagem, juntamente com as novas legislações e exigências, trouxeram a necessidade de reformulação dos Projetos Político-Pedagógicos (PPP) dos cursos de graduação em saúde, visando a "melhoria da formação dos profissionais de saúde e da intenção de contribuir para um processo de melhoria do cuidado à saúde das pessoas e comunidades [...], um movimento que uma vez iniciado, deve ser permanente" (KOMATSU et al., 2003, p. 5).

Os cursos da saúde passaram a introduzir em seus PPP as metodologias ativas, que "são consideradas tecnologias que proporcionam engajamento dos educandos no processo educacional e que favorecem o desenvolvimento de sua capacidade crítica e reflexiva em relação ao que estão fazendo" (LIMA, 2017, p. 424).

Assim, os cursos de graduação em enfermagem vêm buscando alternativas pedagógicas inovadoras que possam consolidar uma formação mais coerente com o perfil profissional desejado para o cotidiano dos serviços de saúde. Uma das alternativas adotadas por algumas escolas de enfermagem do país é a metodologia conhecida como tutorial, que são as atividades de orientação pessoal, acadêmica e profissional formuladas pelo professor e que devem comprometer a participação de todos e que consiste nas características: suporte pessoal durante o desenvolvimento da identidade profissional; compreensão de que os aspectos pessoais, acadêmicos, vocacionais, sociais estarão presentes, os quais devem ser considerados e que a atitude é de troca, de reflexão (ARGÜIS et al., 2002; BELLODI; MARTINS, 2005).

Ao criar um ambiente propício para que o estudante alcance seus objetivos o professor no papel de tutor o estimula a ser responsável pelo desenvolvimento de sua consciência e o pensamento crítico para a resolução de problemas (GOPEE, 2011). Neste contexto o papel do professor /tutor/ facilitador, é "zelar pelo desenvolvimento satisfatório do processo de ensino - aprendizagem” (KOMATSU et al., 2003, p. 20).

Este estudo propôs demonstrar o uso do tutorial como metodologia de aprendizagem para a formação em Enfermagem, no aspecto da apreensão de uma postura crítica em relação à realidade do setor saúde. Enquanto metodologia de ensino aprendizagem buscou-se conhecer a satisfação/aceitação dele por parte do estudante. 


\section{PERCURSSO METODOLÓGICO}

Delineou-se um Estudo de Caso com abordagem quantitativa e qualitativa, (método misto), cujos sujeitos foram trinta e seis estudantes do segundo ano e vinte e quatro estudantes do quinto ano de um curso de graduação em enfermagem que tiveram o tutorial no módulo da matriz curricular direcionado a Saúde Coletiva e que aceitaram, por meio de Termo de Consentimento Livre e Esclarecido, participar da realização desta pesquisa.

Os dados foram construídos no período de dois meses e sua apreensão se deu por meio de uma Escala de Likert sobre a vivência no tutorial. A escala de Likert busca "verificar o nível de concordância do sujeito com uma série de afirmações que expressem algo favorável ou desfavorável em relação a um objeto psicológico" (COLARES et al., 2002, p. 196). Este nível de concordância é mensurado por meio da escolha da opção que mais expresse a opinião do sujeito: 1- Discordo totalmente; 2-Discordo; 3- Nem concordo, nem discordo; 4-Concordo ou 5- Concordo totalmente.

Os dados obtidos foram transformados em porcentagem e analisados com a análise de variância One-way (One Way ANOVA) por meio do teste de Kruskal-Wallys e pós-teste de comparação múltipla de Dunn's. Os histogramas foram apresentados como mediana e menor/maior valores, o que permitiu uma melhor visualização e comparação das informações.

Para conhecer a postura crítica do estudante frente a uma situação do cotidiano, problematizou-se uma situação que envolvia uma adolescente grávida do segundo filho, sem o companheiro e que precisava trabalhar para o sustento da família. Esta situação foi apresentada ao aprendiz e este deveria elencar, por escrito, suas ações como enfermeiro na condução do caso.

Os dados construídos por meio da leitura das respostas dos estudantes foram submetidos à análise de conteúdo, que significa a análise dos “significados”, podendo ser, também, uma análise dos “significantes" (BARDIN, 2011).

Com o objetivo de preservar a privacidade dos sujeitos durante as falas, todas as respostas foram codificadas e cada um dos sujeitos que respondeu recebeu o codinome de uma flor. 0 presente estudo foi submetido ao Comitê de Ética em Pesquisa por meio da Plataforma Brasil e aprovado sob protocolo no 12572813.5.0000.5013.

\section{RESULTADOS}

\subsection{AVALIAÇ̃̃O DO TUTORIAL PELO DISCENTE}

As medianas (respostas centrais) obtidas de cada eixo dos dados das tabelas foram apresentadas na forma de histograma com o comparativo entre o segundo e quinto ano dos itens: concordância, discordância e neutralidade ("nem concordo, nem discordo"). Os dados que referem itens de oposição (concordância e discordância) foram simplificados em apenas duas categorias - Método do Qui-Quadrado - pela união das categorias concordo totalmente e concordo, e pela união das categorias discordo totalmente e discordo. 
Gráfico 1 - Análise do eixo 1

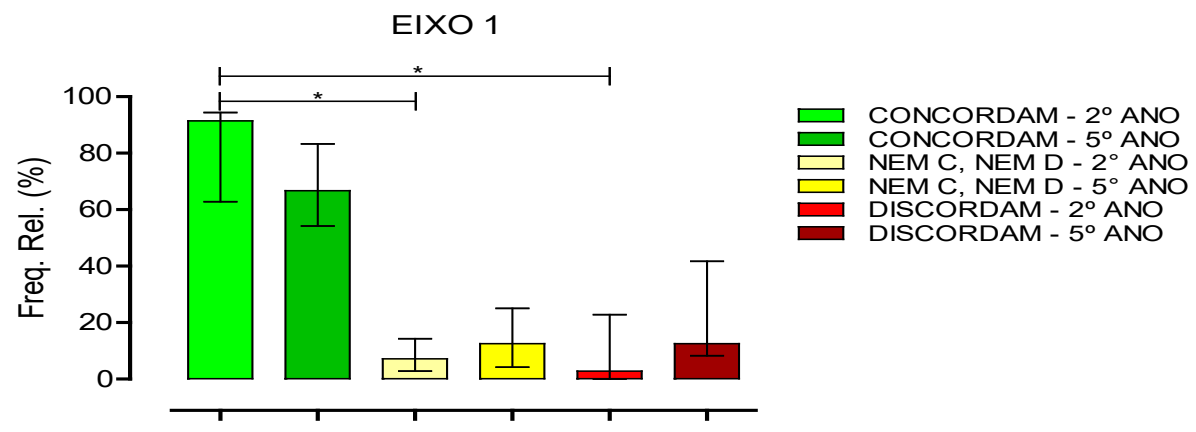

Legenda: Comparativo do $2^{\circ}$ e $5^{\circ}$ anos de enfermagem: acompanhamento das necessidades do estudante pelo tutor. Mediana dos dados analisados estatisticamente pelo teste não-paramétrico de Kruskal-Wallys, seguido do pós teste de comparação múltipla de Dunn e considerando o intervalo de confiança de 95\%. CT: concorda totalmente. C: concorda; NC/ND: nem concorda, nem discorda; D: discorda; DT: discorda totalmente; *: $p<0,05$; Itens avaliados: disponibilidade do professor em atividades extraclasse; estímulo para que a estudante participe das atividades; integração com os demais estudantes; integração da teoria com a prática.

Fonte: Dados da pesquisa.

A análise deste Gráfico aponta que no Eixo 1 prevalece a concordância nas respostas dos discentes tanto do segundo como do quinto ano letivo, ocorrendo em menor número em ambas as turmas a escolha das respostas de neutralidade ("nem concordo, nem discordo") e de discordância. Porém, a análise estatística mostra que há significância apenas nas respostas dos estudantes do segundo ano, quando se compara os dados de concordância com "nem concordo, nem discordo" $(p<0,05)$ e com a discordância $(p<0,05)$. Enquanto os dados gerados pelos estudantes do quinto ano em todas as comparações não foram significativos. 




Legenda: Comparativo do $2^{\circ}$ e $5^{\circ}$ anos de enfermagem: avaliação do tutorial. Mediana dos dados analisados estatisticamente pelo teste não-paramétrico de Kruskal-Wallys, seguido do pós teste de comparação múltipla de Dunn e considerando o intervalo de confiança de 95\%. CT: concorda totalmente. CT: concorda totalmente; C: concorda; NC/ND: nem concorda, nem discorda; D: discorda; DT: discorda totalmente; *: $p<0,05$; Itens avaliados: permitir a leitura prévia dos assuntos; a discussão em sala de aula; exposição de opiniões; interação com outros profissionais.

Fonte: Dados da pesquisa.

No Eixo 2 foi possível visualizar que 100\% dos estudantes do segundo ano concordam com as afirmações e $80 \%$ dos estudantes do quinto ano, também concordam. Apenas um pequeno número de estudantes no quinto ano discorda. Assim como no Eixo 1 a análise estatística mostra significância nas respostas dos estudantes do segundo ano quando se compara aqueles que concordam com aqueles que "nem concordo, nem discordo" e com os que discordam.

No quinto ano não houve significância entre os grupos que concordam, discordam, e "nem concordam e nem discordam". De uma maneira geral os estudantes apontam como vantagens do tutorial, as estratégias didáticas como a possibilidade de realizar leitura prévia de textos; a discussão dos assuntos em sala de aula; a exposição de diferentes opiniões e a interação com profissionais de diferentes áreas de atuação. 
Gráfico 3 - Análise do eixo 3

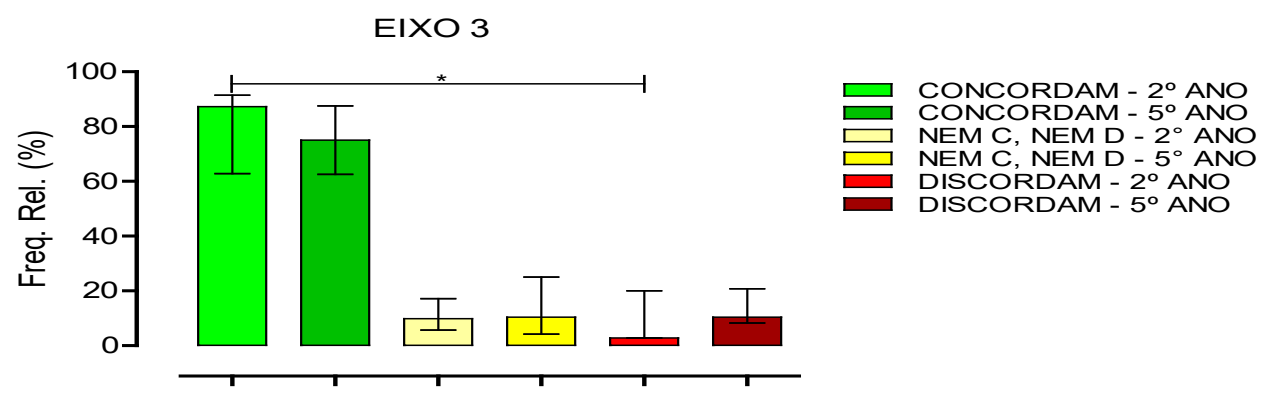

Legenda: Comparativo do $2^{\circ}$ e $5^{\circ}$ anos de enfermagem: facilitação do aprendizado, tornando o estudante mais crítico. Mediana dos dados analisados estatisticamente pelo teste não-paramétrico de Kruskal-Wallys, seguido do pós teste de comparação múltipla de Dunn e considerando o intervalo de confiança de $95 \%$. CT: concorda totalmente. CT: concorda totalmente; C: concorda; NC/ ND: nem concorda, nem discorda; D: discorda; DT: discorda totalmente; *: $p<0,05$; Itens avaliados: participação ativa do discente nas discussões; pela leitura de textos; pela resolução de problemas; por meio das atividades práticas.

Fonte: Dados da pesquisa.

Quanto à opinião do estudante referente à construção da sua análise crítica frente à realidade do setor saúde por meio de sua vivência nos tutoriais e a facilitação do aprendizado, conforme apresentado no Eixo 3, percebe-se uma prevalência da concordância dos dois anos letivos (88\% e 75\%, respectivamente), apontando assim que, para os estudantes, sua postura crítica se desenvolveu por meio de sua participação ativa nas discussões, pela leitura de textos, pela resolução de problemas ou por meio das atividades práticas. Além disso, a discordância e a afirmativa "nem concordo, nem discordo" tanto para o segundo como para o quinto ano aparecem em frequência bem diminutas ( $4 \%$ e $9 \%$, respectivamente para o segundo ano e $2 \%$ e $8 \%$, respectivamente para o quinto ano).

No entanto, somente a resposta dos estudantes do segundo ano de concordância quando comparada com a discordância mostrou significância. Para os estudantes do quinto ano, mais uma vez, não ocorreu significância entre os grupos que concordam, discordam, e "nem concordam e nem discordam". 
Gráfico 4 - Análise do eixo 4

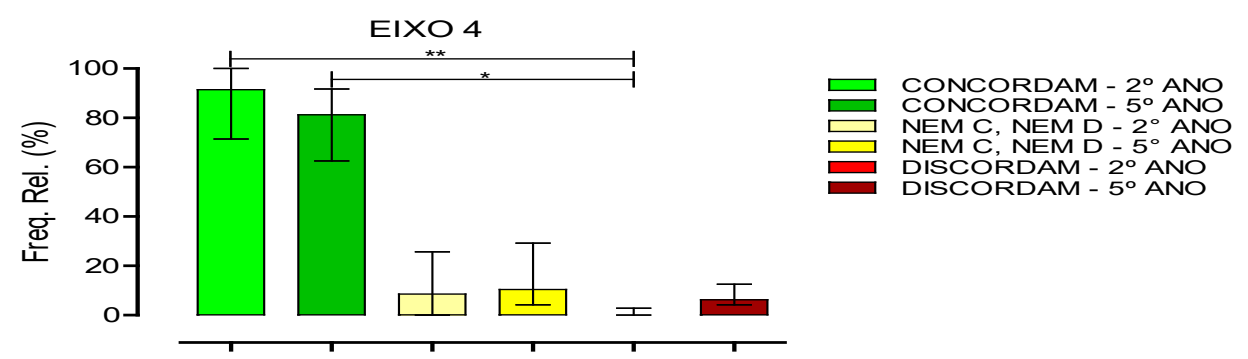

Legenda: Comparativo do $2^{\circ}$ e $5^{\circ}$ anos de enfermagem: participação do estudante no tutorial. Mediana dos dados analisados estatisticamente pelo teste não-paramétrico de Kruskal-Wallys, seguido do pós teste de comparação múltipla de Dunn e considerando o intervalo de confiança de 95\%. CT: concorda totalmente. CT: concorda totalmente; C: concorda; NC/ND: nem concorda, nem discorda; D: discorda; DT: discorda totalmente; *: $p<0,05 ;{ }^{* *}$ : $p<0,01$; Itens avaliados: satisfação com o método; aprovação do método; acolhimento; confiança em expor sua opinião.

Fonte: Dados da pesquisa.

Por fim, pela Escala de Likert o estudante ao avaliar a sua participação no tutorial também manteve a concordância em maior número em suas respostas, $92 \%$ no segundo ano e $80 \%$ no quinto ano, com uma menor frequência de estudantes do segundo e quinto ano, optando pelo "nem concordo, nem discordo" ( $9 \%$ e 10\%, respectivamente), e menor ainda pelo "discordo" (0\% e 7\%, respectivamente).

Neste eixo, a significância dos dados gerados pela análise das respostas do segundo ano e do quinto ano ao comparar a frequência daqueles que concordam com aqueles que discordam do quinto ano, mostra que ambos os anos sentem que o tutorial estimula e/ou "força" a participação dos estudantes no processo de aprendizagem o que demonstra a relevância do método.

\subsection{A PROBLEMATIZAÇÃO}

Durante o processo da leitura de todas as respostas à situação-problema pelos discentes, observou-se que eles estabeleceram com coerência as ações esperadas pelo enfermeiro, demonstrando capacidade crítica, que conforme elencado pelas DCN espera-se do enfermeiro formação crítica (desenvolver suas ações com objetividade, tomando decisões com competência) e formação reflexiva (unindo sua postura ética a sua tomada de decisão) (SANTOS, 2006).

Para que o estudante desenvolva esta capacidade crítica ele precisa se esforçar e sair do mundo reducionista e limitado em si mesmo e passar a ver a realidade do outro, já que "a primeira condição para que um ser possa assumir um ato comprometido está em ser capaz de agir e refletir”; sendo assim, quando o estudante reflete sobre um problema e realiza suas ações com visão holística, ele é capaz de se comprometer com a situação de saúde (FREIRE, 1983, p. 6). 
Ao se narrar a situação da adolescente gestante procurou-se entender a percepção crítica desenvolvida pelos estudantes. Elaborou-se um padrão esperado de respostas que englobasse cuidados com a saúde da gestante (pré-natal, planejamento familiar, alimentação, descanso, cuidados com a água e alimentos); encaminhamentos necessários (para outros profissionais, como médico, assistente social, nutricionista, odontólogo); orientações e providências referentes à sua família: companheiro e filhos (que pode envolver bolsa família, grupos de comunidade, entre outros).

Os dados construídos a partir da resposta dos estudantes à situação problema possibilitou elencar as seguintes categorias: atendimento às necessidades de saúde e de vida; atendimento a um foco de necessidade de saúde ou de vida; desmotivação com a prática acadêmica e profissional.

\section{Categoria 1: Atendimento às necessidades de saúde e de vida}

Os estudantes estabeleceram as ações do enfermeiro do ponto de vista da saúde e social com capacidade crítica como pode ser percebido nas respostas:

[...] promover uma assistência a família, mostrando o caminho por onde devem percorrer. Promover uma orientação sexual disponibilizando métodos contraceptivos para prevenir uma nova gravidez; fazer o acompanhamento do pré-natal; promover junto com nutricionistas um acompanhamento nutricional a família levando em consideração as condições de vida; ajudar no cadastramento do bolsa escola. (LAMTANA, $2^{\circ}$ ano).

[...] acolher esta família em Unidade Básica de Saúde; promover consultas de enfermagem e médica a toda a família; realizar orientações obre o processo saúde-doença; estimular a consulta de puericultura aos filhos; integrar essa família a rede de cursos e incentivo à renda; realizar orientações de planejamento familiar; realizar pré-natal e acompanhamento até o puerpério; orientações sobre o modo de higienização de água e alimentos; promover o abastecimento de água adequada; estimular alimentação saudável e estímulo à escola das crianças. (AZALÉlA, $5^{\circ}$ ano).

É possível sugerir que a metodologia do tutorial consegue formar cidadãos capazes de aplicar na prática os saberes, desenvolvendo a capacidade de compreender a realidade do mundo e propor soluções para ela (NOBREGA-THERRIEN et al., 2010). Dentro desta metodologia esta formação ocorre por meio da orientação próxima e permanente ao estudante durante a sua formação profissional, guiando seus estudos, reforçando suas atividades teórico-práticas e tornando possível que ele identifique os problemas do sujeito inserido na realidade do setor saúde e use suas habilidades e competências para prestar uma assistência de qualidade.

Os textos demonstram respostas bastante semelhantes entre os estudantes iniciantes e os do final do curso, podendo sugerir que o processo desenvolvido no tutorial é adequado para o desenvolvimento paulatino do pensamento crítico desde o início da graduação. Por outro lado, observou-se na resposta dos formandos o mesmo nível de amadurecimento técnico dos colegas mais jovens. Um maior aprofundamento técnico acrescido de outras competências como preocupação e sentimentos de humanização que o problema tinha embutido não foi observado. 
Os egressos das profissões de saúde devem estar, atualmente, preparados e comprometidos com a nossa realidade. Neste sentido o aluno submetido à metodologia tutorial deve ser sujeito do seu processo de formação. Assim como outros processos, reforçando novamente a capacidade de aprender a aprender; de ser capaz de articular seus conhecimentos com suas habilidades e atitudes; de saber buscar informações para resolver problemas e agir com eficiência, unindo os conhecimentos previamente adquiridos com a capacidade de inovar (SILVA et al., 2010).

\section{Categoria 2: Atendimento a um foco de necessidade: de saúde ou de vida}

Nos textos dos estudantes evidenciaram-se ações do enfermeiro que não englobavam as necessidades de saúde e sociais da gestante adolescente descrita na situação-problema.

[...] podemos cuidar da menina até o final de sua gestação acompanhando seus sintomas, pré-natal. (SÁLVIA, $2^{\circ}$ ano).

[...] encaminharia a gestante apara a avaliação nutricional. [...] Orientaria a gestante ao auto cuidado corporal e com os alimentos. [...] Solicitaria exames para avaliar as defesas da gestante. (CAMÉLIA, $5^{\circ}$ ano).

As respostas dos estudantes atenderam também apenas a outro foco de atendimento, sendo voltado para as necessidades de vida, como evidenciado: “[...] Acionaria o conselho tutelar [...] o cadastro dela no bolsa família (ORQUÍDIA, $2^{\circ}$ ano).

Nas respostas dos enfermeirandos, ainda que demonstrassem a capacidade crítica para atender todas as necessidades da adolescente gestante, detiveram-se basicamente em cumprir a assistência técnica. Dessa maneira, sugere-se repensar as metodologias, processos de avaliação contínuos e estratégias para manutenção do interesse e aplicabilidade prática do conhecimento construído.

0 professor deve ser capaz de selecionar as oportunidades de aprendizagem; identificar os recursos didáticos disponíveis para o alcance dos objetivos educacionais e assim permitir ao estudante 0 desenvolvimento das competências necessárias como ética, gestão e prestação de cuidados (GOPEE, 2011), não apenas no início do curso ou nos momentos dos tutoriais e em outras metodologias.

Paralelamente o estudante tem que ser corresponsável pela sua aprendizagem. Pelas reflexões e ações implementadas, pois a "legitimação da voz que é dada a cada uma das partes, pela percepção de que o conhecimento pode e deve ser construído numa relação mais horizontal entre seus atores" (SANTANA et al., 2009, p. 178).

Evidenciou-se esta preocupação restrita ao foco social nas falas de alguns estudantes do segundo ano, fato esperado por eles estarem no início da graduação. Mas como outros discentes da mesma turma também apresentaram respostas que englobaram tanto as necessidades de vida como de saúde, questiona-se assim o caminho de aprendizagem trilhado por este estudante.

As afirmações acima demostram que o estudante deve buscar um maior compromisso e responsabilidade, para que o conhecimento não esteja apenas centrado em uma queixa do paciente, mas que o veja como um todo, buscando a resolubilidade de suas necessidades. Esta é a necessidade da 
sociedade atual: "de profissionais que atuem como sujeitos sociais comprometidos com a democracia e a emancipação humana. Sujeitos capazes de inovar, mas, sobretudo, de humanizar as inovações" (SILVA et al., 2010, p. 182).

\section{Categoria 3: Desmotivação com a prática acadêmica e profissional}

Alguns estudantes de ambos os anos letivos preencheram o espaço para análise do caso com as repostas "não sei responder", "não desejo responder" ou ainda "não sei opinar”. Isto pode sugerir duas opções: o estudante não se sentiu seguro o suficiente para construir uma resposta, apontando as ações do enfermeiro frente ao caso ou não desejou realmente responder a questão por desmotivação ou comodismo.

A opção referente à insegurança do estudante em responder o caso traz consigo o questionamento de que ele não respondeu por que houve falha no método, não tendo ele o suporte necessário para sua formação crítica?

Remete-se a necessidade da avaliação e reflexão constante da relação tutor-tutorando, bem como das estratégias que são utilizadas no tutorial para construção da aprendizagem, para que as dificuldades possam ser percebidas, discutidas e corrigidas, pois “a avaliação precisa ser, antes de tudo, processual e formativa para a inclusão, autonomia, diálogo e reflexões coletivas, na busca de respostas e caminhos para os problemas detectados" (MITRE et al., 2008, p. 2138).

A escolha de não responder o estudo de caso pode ainda sugerir o desestímulo do estudante com a formação acadêmica, que pode ocorrer pela sobrecarga de atividades extracurriculares, pela matriz curricular exaustiva do curso, a insatisfação com a metodologia que está sendo trabalhada ao longo de todos os anos do curso ou ainda o desinteresse com a sua aprendizagem.

Ressalta-se que "a primeira condição para que um indivíduo possa assumir um ato comprometido está em ser capaz de agir e refletir” (FREIRE, 1983, p. 6), evidenciando a importância da participação ativa do estudante, pois ele pode em sua vida acadêmica não se comprometer a refletir e agir frente à realidade da sociedade, tendo chances de se tornar um profissional com um comprometimento igualmente ausente e ineficaz, cabendo assim ao professor estimular nas vivências do tutorial este interesse do estudante em apreender a realidade, refleti-la e intervir com ações de comprometimento.

O estudante é responsável pela construção do seu conhecimento, levantando hipóteses e testando-as, ou seja, sendo sempre um estudante ativo, por meio de sua relação com o mundo, na percepção de sua realidade e na compreensão do conhecimento (RIBEIRO, 2009), mostrando a importância do seu compromisso com o aprendizado durante toda a sua formação acadêmica e também sua responsabilidade com as estratégias que o tutor utiliza em sala de aula, tanto no sentido de participação efetiva, como de avaliação destas metodologias que são utilizadas em aulas teóricas e práticas.

Entretanto, assim como o papel do estudante é questionado, o do professor também é, visto que o mesmo no tutorial é responsável pela formação acadêmica, profissional e pessoal do discente, devendo "preparar os estudantes com uma sólida formação teórica que fundamente sua atuação nos campos de estágio e, futuramente, na sua vida profissional” (GOMES et al., 2010, p. 182).

0 professor deve ser capaz de selecionar as oportunidades de aprendizagem, identificar os recursos disponíveis para o alcance dos objetivos de aula e assim permitir ao estudante o desenvolvimento 
das competências necessárias para se tornar o profissional que a sociedade precisa: ética, gestão e prestação de cuidados (GOPEE, 2011).

Os resultados de ambas as análises convergem para a percepção de que a metodologia do tutorial vivenciada pelos estudantes tem o potencial para promover o desenvolvimento de uma capacidade mais crítica e reflexiva. Os resultados mostram que tanto os estudantes iniciantes e concluintes gostam de ser mentorados e têm uma apreensão adequada dos conteúdos fornecidos.

No entanto, é possível sugerir que com a suspensão do monitoramento devido mudança de disciplinas os estudantes parecem entrar em processo de desinteresse, pois eles aparentam ser tecnicamente adequados ao conteúdo ministrado. Sabem o que tem que ser feito, contudo não aprofundam e não parecem transpor para a realidade.

Nas duas análises é possível, ainda, perceber a diminuição do interesse do estudante do quinto ano com as vivências do tutorial, tanto pela predominância da não significância dos dados estatísticos, que apesar de prevalecer respostas de concordância em todos os eixos aparecem em maior número as respostas de discordância e de neutralidade ("nem concordo, nem discordo") quando comparado com as respostas dos estudantes do segundo ano, quanto pelas falas na resolução da situação problema, destacando-se mais uma vez a necessidade da avaliação constante das metodologias utilizadas e dos sujeitos envolvidos.

Por esta razão, se faz necessário sempre avaliar a dinâmica e a organização do tutorial e a relação entre tutor e tutorando, que constitui seu eixo principal (BELLODI; MARTINS, 2005), desde o início dos tutoriais e ao término de cada encontro, pois só assim serão percebidas as lacunas de aprendizagem e a diminuição do interesse, participação e compromissos dos sujeitos, permitindo a reformulação das ações.

\section{DISCUSSÕES}

\subsection{AVALIACÃO DO TUTORIAL PELO DISCENTE}

As afirmações sugerem, pela prevalência da concordância das repostas no Gráfico 1, que para os estudantes o acompanhamento de suas necessidades pelo tutor é um fato positivo, seja pela disponibilidade do professor em atividades extraclasse, pelo estímulo a sua participação nas atividades, pela promoção a interação com outros estudantes e pela integração entre teoria e prática, ressaltando a importância de que o professor atenda a necessidade da dimensão cuidativa que o estudante apresenta ao vivenciar o tutorial (SAUPE; GEIB, 2002).

Portanto, o professor atua como o guia, como o orientador dos passos a serem seguidos pelo estudante e para que este encaminhamento ocorra de maneira positiva, levando ao crescimento profissional e pessoal do estudante, o tutor tem que ter interesse e disponibilidade para acompanhar o estudo, esclarecer dúvidas e quando necessário reorientar as atividades que estão sendo realizadas pelo discente no ambiente extraclasse. A intervenção do professor ocorre internamente e nas interações dos seus alunos com os diversos sujeitos, para assim favorecer a construção do saber (RIBEIRO, 2009). 
No Gráfico 2 os julgamentos remetem ao fato de que o discente visualiza como vantagem no tutorial aquilo que depende da sua participação e interesse em vivenciar as experiências propostas pelo professor, corroborando o seu papel central nesta metodologia, onde o estudante deve ser proativo, capaz de articular e comunicar as suas necessidades, de ter autonomia e de discutir os caminhos para o seu crescimento e da sua relação com o tutor ao longo da sua graduação. Além disso, o tutorando deve ser capaz de se expor, de se arriscar e de desenvolver independência de julgamento e de tomada de decisão ao longo do tempo (BELLODI; MARTINS, 2005).

Os resultados obtidos no Gráfico 3 sugerem a importância do tutorial na formação do estudante, possibilitando ao mesmo a responsabilidade pela construção do seu saber, por meio da aquisição de conhecimentos teóricos e baseando-se na observação da realidade e na reflexão crítica sobre os sujeitos, fazendo com que os conteúdos teóricos sejam aprendidos em conexão com a prática (GOMES et al., 2010).

Por outro lado, observou-se que um pequeno percentual de estudantes demonstrou desinteresse em manter a participação no tutorial. Alguns eventos podem apenas sugerir este pensamento como a própria resistência individual ao método e desconhecimento sobre as vantagens futuras em sua formação; carga horária excessiva ao final do curso; metodologia tradicional, ocorrendo em paralelo em outros módulos e a interpretação errônea de que o conhecimento está sendo transmitido pronto pelo professor é mais fácil, rápido e sem esforço.

Isto nos remete a importância de que o método seja constantemente avaliado pelos docentes e estudantes, pois no ambiente de aprendizagem o estudante tem a oportunidade de construir o seu agir sobre situações e desafios, levantando hipóteses e testando-as (RIBEIRO, 2009), mostrando o compromisso dele com o seu aprendizado e com as estratégias que o tutor utiliza em sala de aula para facilitar a sua apreensão a realidade.

O Gráfico 4 sugere fatos como a satisfação e a aprovação do discente em relação ao tutorial e a sua confiança em expor a sua opinião demonstram que esta metodologia gera mudanças positivas sobre o tutorando como a motivação pelo aprender; menos estresse; maior autoestima; mais informação sobre sua formação profissional, melhor desempenho, maior capacidade em solucionar problemas; maior segurança nas suas escolhas e confiança (BELLODI; MARTINS, 2005). Isto remete a necessidade de que os cursos de graduação utilizem na formação do enfermeiro metodologias que possuam atividades estimuladoras da criatividade e de superação de obstáculos por parte dos estudantes (SILVA et al., 2010).

Durante a análise observou-se que alguns estudantes optaram por responder a afirmativa "nem concordo e nem discordo”. Esta opção pode levar a várias interpretações desde realmente a não aprovação do método tutorial até mesmo desinteresse e certo comodismo para refletir sobre a afirmativa.

Essa realidade pode ser solucionada ou minimizada por meio da aplicação de avaliações com feedback ao estudante, visando compreender os motivos associados a estas respostas. Destaca-se assim o papel do tutor de conhecer o estudante sob seus cuidados, para que assim possa optar por outras estratégias de despertar o interesse na aprendizagem e participação das atividades propostas. Existem várias estratégias para estruturas às intenções educacionais, mas o ponto chave de sucesso é a boa relação professor-aluno (ZABALA, 1998). 
O professor/educador possui várias funções como tutor, mas é necessário ter conhecimento da carreira e do psicossocial do estudante, compreendendo as necessidades, situações e variedades em que cada estudante está incluso, exercendo, assim, também os papéis de conselheiro e orientador na vida acadêmica e na carreira - devendo atuar como professor, servir como padrinho, ser anfitrião e guia, ser advogado e ser um modelo ativo (BELLODI; MARTINS, 2005).

\section{CONCLUSÃO}

Esta pesquisa mostrou que o tutorial (mentoring) tem potencial de eficácia na formação do estudante. 0 processo de acompanhamento do estudante sob todos os seus aspectos é um processo complexo, cuidadoso que exige preparação do docente/tutor e compromisso entendimento do aprendiz. 0 tutorial não é o único, nem talvez o melhor programa de ensino-aprendizagem, mas os resultados demonstraram o potencial para o melhor desenvolvimento do profissional que queremos formar para a sociedade.

Ressalta-se, ainda, a necessidade da avaliação constante da metodologia aplicada pelos sujeitos envolvidos e do preparo do estudante para o encerramento do tutorial, sendo ele estimulado a manter o compromisso com a sua formação profissional. Problematizar uma situação para verificar o potencial crítico e reflexivo dos nossos estudantes pode não ter sido o suficiente para generalizar, mas é o que foi possível apreender.

Assim, os resultados apresentados nesta pesquisa remetem que o tutorial é uma opção metodológica favorável ao processo ensino-aprendizagem, requerendo ainda aperfeiçoamentos do professor, no sentido de ampliar a sua visão para alcançar os objetivos de aprender dos alunos e de criar vínculo de empatia com seus discentes, visto que apenas uma relação desta maneira permitirá conhecê-los.

Nesta realidade, o aluno também tem que ter a mesma visão, de confiar no seu tutor e de demonstrar o seu verdadeiro "eu", com suas fragilidades e qualidades. E acima de tudo, o discente tem que querer aprender e viver a graduação ao máximo, para formar sua carreira acadêmica, pessoal e profissional. Por isto o estudo remete ainda a necessidade de avaliação das fragilidades da metodologia na percepção docente e discente

\section{REFERÊNCIAS}

ARGÜIS, R. et al. Tutoria: com a palavra, o aluno. Tradução: Fátima Murad. V. 6. Porto Alegre: Artmed, 2002.

BARDIN, L. Análise de conteúdo. Tradução de Luis Antero Reto e Augusto Pinheiro. São Paulo: Edições 70, 2011.

BELLODI, P. L.; MARTINS, M. A. Tutoria: mentoring na formação médica. São Paulo: Casa do Psicólogo, 2005. 
BRASIL. Lei n 8.080, de 19 de setembro de 1990. Dispõe sobre as condições para promoção, proteção e recuperação da saúde, a organização e o funcionamento dos serviços correspondentes e dá outras providências. Diário Oficial [da] República Federativa do Brasil, Brasília, DF, 20 set. 1990. Disponível em: http://conselho.saude.gov.br/ legislacao/lei8080_190990.htm. Acesso em: 26 out. 2011.

COLARES, M. F. A. et al. Construção de um instrumento para avaliação das atitudes de estudantes de medicina frente a aspectos relevantes da prática médica. RBEM. Rio de Janeiro, v. 26, n. 194 p. 194-203, set./dez. 2002.

FERNANDES, J. D. et al. Diretrizes curriculares e estratégias para implantação de uma nova proposta pedagógica. Rev. Esc. Enferm. USP, São Paulo, v. 39, n. 4, dez. 2005. http://dx.doi. org/10.1590/S0080 62342005000400011. Disponível em: http://www.scielo.br/scielo.

php?script=sci_arttext\&pid=S008062342005 000400011\&lng=en\&nrm=iso. Acesso em: 8 set. 2012 .

FEURWERKER, L. C. M. Educação dos profissionais de saúde hoje: problemas, desafios, perspectivas e as propostas do Ministério da Saúde. Revista da Associação Brasileira de Ensino Odontológico, Paraná, 2003. p. 24-27

FREIRE, P. Educação e mudança. Tradução: Moacir Gadotti e Lilian Lopes Martin, Rio de Janeiro: Paz e Terra, 1983.

GOMES, M. P. C. et al. O uso de metodologias ativas no ensino de graduação nas ciências sociais e da saúde: avaliação dos estudantes. Ciênc. Educ., Bauru, v. 16, n. 1, 2010. http://dx.doi.org /10. 1590/S1516-73132010000100011.Disponível em: http://www.scielo.br/scielo.php?script=sci_arttex t\&pid=S151673132010000100011\&lng=en\&nrm=iso. Acesso em: 7 jun. 2013.

GOPEE, N. Mentoring and supervision in healthcare. 2. ed. London: SAGE, 2011.

KOMATSU, R. S. et al. Guia do processo de ensino-aprendizagem: aprender a aprender. 4. ed. Marília: Faculdade de Medicina de Marília, 2003.

LIMA, Valéria Vernaschi. Espiral construtivista: uma metodologia ativa de ensinoaprendizagem. Interface, Botucatu, v. 21, n. 61, p. 421-434, jun. 2017. http://dx.doi. org/10.1590/1807-57622016.0316. Disponível em: http://www.scielo.br/scielo.php?script=sci_ arttext\&pid=S1414-32832017000200421\&lng=en\&nrm=iso. Acesso em: 19 set. 2019.

MITRE, S. M. et al. Metodologias ativas de ensino-aprendizagem na formação profissional em saúde: debates atuais. Ciênc. Saúde Coletiva, Rio de Janeiro, v. 13, supl. 2, dez. 2008. http://dx.doi. 
org/10.1590/S1413-81232008000900018. Disponível em: http://www.scielo.br/scielo.php?script=sci_ arttext\&pid=S1-41381232008000900018\&lng=en\&nrm=iso. Acesso em: 18 mar. 2014.

NOBREGA-THERRIEN, S. M. et al. Projeto Político Pedagógico: concepção, construção e avaliação na enfermagem. Rev. Esc. Enferm. USP, São Paulo, v. 44, n. 3, set. 2010. http://dx.doi.org/10.1590/ S0080-62342010000300018. Disponível em: http://www.scielo.br/scielo.php?script=sci_ arttext\&pid=S0080-62342010000300018\&lng=en\&nrm=iso. Acesso em: 7 jun. 2013.

RIBEIRO, J. G. C. G. Prática docente: intervenções de facilitação nos processos de aprendizagem. Maceió: EDUFAL, 2009.

SANTANA, C.S. et al. Reflexões sobre a prática de tutoria com estudantes de terapia ocupacional. Trab. Educ. Saúde, Rio de Janeiro, v. 7, n. 1, jun. 2009. http://dx.doi.org/10.1590/ S198177462009 000100009. Disponível em: http://www.scielo.br/scielo.php?script=sci_arttextepid =S198177462009000100009 \&lng=en\&nrm=iso. Acesso em: 4 nov. 2013.

SANTOS, S. S.C. Perfil de egresso de curso de enfermagem nas diretrizes curriculares nacionais: uma aproximação. Rev. Bras. Enferm., Brasília, v. 59, n. 2, abr. 2006. http://dx.doi.org/10.1590/ S0034 71672006000200018. Disponível em: http://www.scielo.br/scielo.php?script=sci_ arttext\&pid=S003471672006000200018\&lng=en\&nrm=iso. Acesso em: 7 jun. 2013.

SAUPE, R.; GEIB, L. T. C. Programas tutoriais para os cursos de enfermagem. Rev. LatinoAm. Enfermagem, Ribeirão Preto, v. 10, n. 5, out. 2002. http://dx.doi.org/10.1590/S010411692002000500015. Disponível em: http://www.scielo.br/scielo.php?script=sci_arttext\&pid=S010 $411692002000500015 \& l n g=e n \& n r m=i s o$. Acesso em: 8 set. 2012.

SILVA, M.G. et al. Processo de formação da(o) enfermeira(o) na contemporaneidade: desafios e perspectivas. Texto Contexto - Enferm., Florianópolis, v. 19, n. 1, mar. 2010. http://dx.doi. org/10.1590/S01040707 2010000100021. Disponível em: http://www.scielo.br/scielo. php?script=sci_arttext\&pid=S01047072010000 100021\&lng=en\&nrm=iso >. Acesso em: 7 jun. 2013.

ZABALA, A. A prática educativa: como ensinar. Tradução: Ernani F. da F. Rosa. Porto Alegre: Artmed, 1998. 
1 Possui graduação em Enfermagem pela Universidade Federal de Alagoas (2006), Especialização em Enfermagem do Trabalho pela Universidade Estadual de Ciências da Saúde de Alagoas e mestrado em Ensino na Saúde pela Faculdade de Medicina da Universidade Federal de Alagoas (2014). Doutorado em andamento em Saúde Pública na Universidade de São Paulo. Atualmente é Professora adjunta I e membro titular do Colegiado do Curso de Enfermagem do Centro Universitário Tiradentes. Docente e membro do Núcleo Docente Estruturante do curso de Enfermagem da Universidade Estadual de Ciências da Saúde de Alagoas. Editora Executiva do Caderno de Graduação - UNIT/ AL - Ciências Biológicas e da Saúde. Email para contato: apaularebelo@hotmail.com

2 fessora Associada IV da Faculdade de Medicina da Universidade Federal de Alagoas. Doutorado em Saúde da Criança e do Adolescente (USP/Faculdade de Medicina de Ribeirão Preto/SP, 2003); Mestrado em Saúde da Criança pela UFAL/ UFS (1995); . Residência Médica em Pediatria (1980), Residência Médica em Nefrologia pediátrica pela Faculdade de Ciencias Médicas da Santa Casa de São Paulo ( 1982); Especialista em Educação das Profissões de Saúde (UFC/ FAIMER Br, 2009);E-mail: camposdelisboa@gmail.com

3 Doutor em Ciências Morfológicas; Professor adjunto IV da Universidade Federal de Alagoas - UFAL.

E-mail: rrodarte@ig.com.br

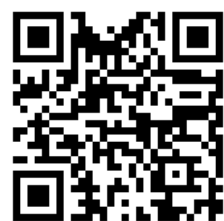

A autenticidade desse artigo pode ser conferida no site https://periodicos. set.edu.br



Este artigo é licenciado na modalidade acesso abertosob a Atribuição-Compartilhalgual CC BY-SA

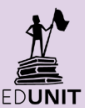

